\title{
Numerical Modelling of the In-Plane Loaded Homogenized Masonry Walls
}

\author{
Sedat Kömürcï ${ }^{1}$, Abdullah Gedikli ${ }^{2}$ \\ ${ }^{1}$ Department of Civil Engineering,Istanbul Technical University \\ ${ }^{2}$ Department of Civil Engineering, Istanbul Technical University
}

\begin{tabular}{l} 
Article Info \\
\hline Article history: \\
Received May $30^{\text {th }}, 2017$ \\
Revised Aug $20^{\text {th }}, 2017$ \\
Accepted Oct $18^{\text {th }}, 2017$ \\
\hline Keyword: \\
Crack \\
Fracture \\
Homogenization \\
Masonry \\
Modelling \\
\hline
\end{tabular}

\begin{abstract}
Masonry structures are one of the oldest structures in the world and have a considerable place among all the structures. Modelling of the masonry structures has become a significant requirement to evaluate the strengths of existing masonry structures and to build modern masonry structures. In this study, in-plane behaviors of the walls which constituting masonry structures are numerically modelled and analyzed. The homogenization technique is applied to obtain the material parameters used in the models. Unreinforced solid masonry wall and masonry wall with an opening are analyzed. The propagations of the cracks which may occur under the in-plane loads on the walls are investigated numerically. Fracture mechanisms occurring in the walls under the effect of in-plane loads are determined as a result of the analyzes.
\end{abstract}

\section{Corresponding Author:}

SedatKömürcü, Department of Civil Engineering, Istanbul Technical University, Ayazağa Campus Civil Engineering Faculty Building, Maslak, 34469 Sarıyer / Istanbul Email: komurcus@itu.edu.tr

\section{Introduction}

Masonry is a composite material that consists of units and mortar. It is necessary to model and analyze the masonry structures to understand them which exposed to many natural hazards especially earthquakes and to construct safe and modern masonry structures. There are several modelling techniques for modelling of walls constituting the masonry structures. Homogenous modelling techniques are suitable and widespread techniques reflecting general masonry behavior. In this study, nonlinear behaviors of walls under the effect of in-plane loads are numerically modelled and analyzed. The homogenization technique is used to model the masonry walls with their composite structures. Masonry walls were modelled and analyzed to determine the fracture mechanisms of the walls. In addition, in-plane behaviors of unreinforced masonry walls were analyzed numerically.

There are many studies about homogenous modelling of masonry structures. Researches have worked for producing homogenous damage models for masonry structures. The effects of in-plane effects on the masonry walls have been investigated by many scientists. Masonry units and mortar are modelled as a single material in the macro modelling technique. The macro modelling technique was studied in [1] and [2]. Researches were created orthotropic damage models in studies [3] and [4]. Lourenço worked on computational modelling of masonry structures using macro modelling technique [5]. Oller were studied on the numerical modelling of masonry walls [6]. Masonry panel wall behavior was studied in [7] and numerical study about strength of masonry was presented in [8]. Macro modelling is a significant modelling method for masonry structures and studies have continued to model masonry walls with homogeneous techniques. 


\section{Homogenization of MasonryWalls}

Modelling of the masonry walls is a special issue because of the different characteristics of masonry units and mortar. There are various techniques to characterize structural behavior of masonry. Masonry structures can be generally modelled as heterogeneous and homogeneous models. Macro modelling technique is known as homogeneous modelling technique. Masonry units (brick, stone etc.) and mortar are represented as a single material with homogenization of masonry wall parts. The homogenous modelling procedure is shown in Figure 1. Composite structure is produced after the homogenization process.

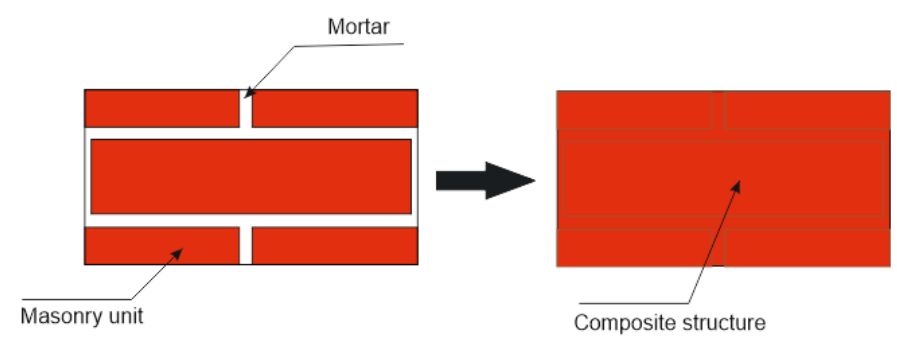

Figure 1. Macro modelling procedure.

Masonry walls are composite structures that can be homogenized using advanced techniques according to the macro modelling technique. It is beneficial to use masonry wall parts which periodically repeat themselves on the wall to model the masonry walls by homogenization. Some periodically repeated masonry wall parts that can be used for homogenization are shown in Figure 2. All the numbered wall parts in Figure 2 is called as elementary wall parts.

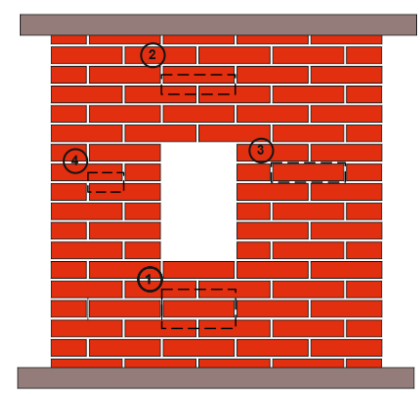

Figure 2. Determination of periodically repeated elementary wall parts.

Elementary wall parts are shown in Figure 3. These elementary wall parts can be used to determine material parameters of the masonry wall using in numerical analysis.
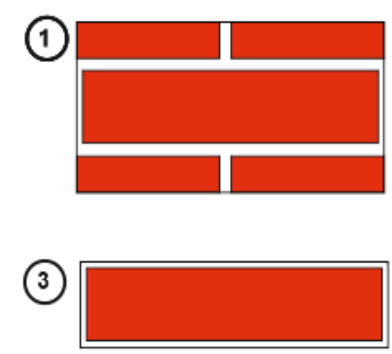

(2)

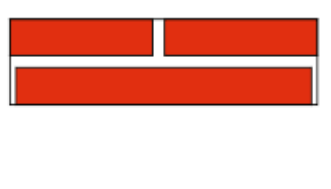

(4)

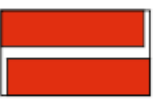

Figure 3. Elementary wall parts.

Homogenization procedure is applicated on an elementary wall part. Application of the homogenization technique is shown in Figure 4. There are two different directions to applicate homogenization because of orthotropic structure of the masonry walls. Elementary wall part can be divided as continuous parts both vertical and horizontal directions. Finally, a composite structure is obtained at the end of the homogenization procedure. 


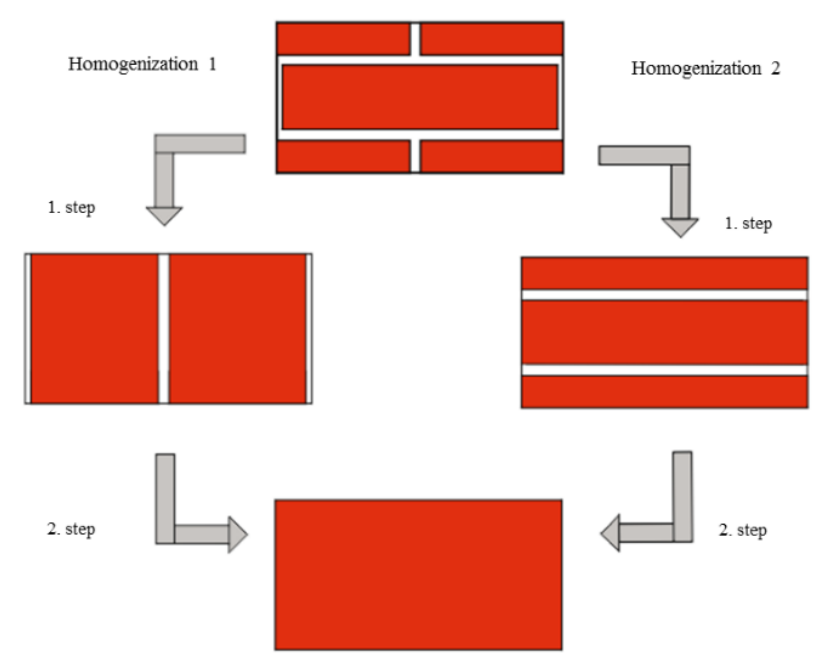

Figure 4. Application of the homogenization technique.

\section{Finite Element Models of Homogenized Masonry Walls}

In this study, finite element analysis was performed in ANSYS software by using homogenization technique on unreinforced masonry walls without and with an opening. Experimental studies were used to build numerical models in the literature [9], [10]. The periodically repeated masonry wall part used in the analysis and the masonry unit using in the wall are shown in Figure 5.

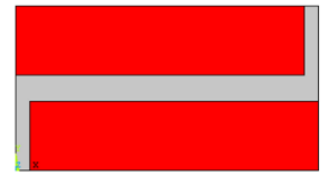

(a)

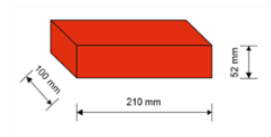

(b)

Figure 5. (a) Elementary wall part (b) Masonry unit.

Elementary wall part was divided to slices as shown in Figure 6.
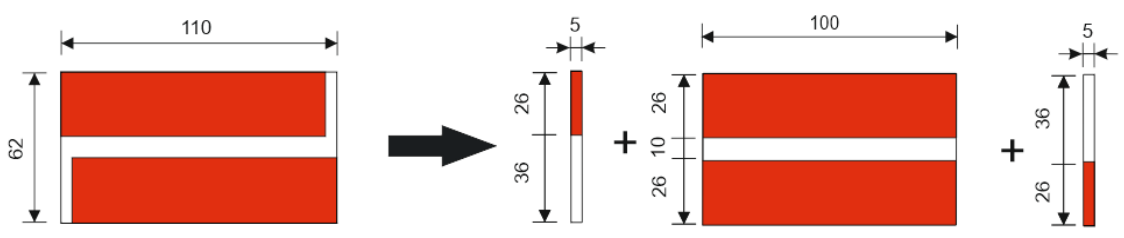

Figure 6. Slicing of the elementary wall part.

All the material units in the slices which obtain from the masonry elementary wall part can be considered as elastic springs as shown in Figure 7.

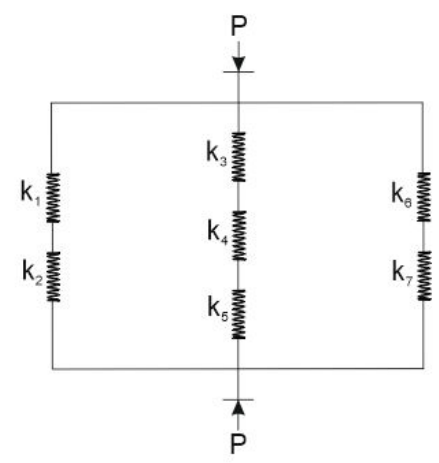

Figure 7. Spring representation of theelementarywallpart.

Themodulus of elasticity of thehomogenizedwallcan be calculatedbyusingspring model. SOLID 65 finite element in the ANSYS software wasusedforthefinite element analysis. This element has 8 nodepointsandeachnodepoint has 3 displacementdegree of freedom in $\mathrm{x}, \mathrm{y}$ and $\mathrm{z}$ directions. It can 
showcollapsemechanismsboth tensile andcompression. Brittlematerials can be modelledsuch as rock, stone, brick, concreteetc. This element is suitableformodelling of nonlinearbehavior of structuresandcracks can be determined in thestructure. Thestructure of the SOLID 65 element is shown in Figure 8.

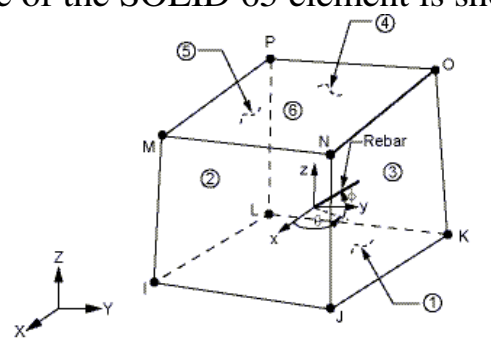

$\begin{array}{lcccc}\text { Materialparametersused } & \text { Figure 8. SOLID 65 element. } & \text { in } \\ \text { themodelsareshown } & \text { in } & \text { Table } & 1 . & \text { Wall } \\ \text { materialparameterswereobtainedwithhomogenization of themasonrywallandwereimplementedtothemacrofinite }\end{array}$ element model.

Table 1. Material properties.

\begin{tabular}{ccccc}
\hline Material & $\begin{array}{c}\text { Modulus of } \\
\text { Elasticity } \\
{[\mathrm{MPa}]}\end{array}$ & Poisson's Ratio & $\begin{array}{c}\text { Tensile Strength } \\
{[\mathrm{MPa}]}\end{array}$ & $\begin{array}{c}\text { Compressive Strength } \\
{[\mathrm{MPa}]}\end{array}$ \\
\hline Brick & 16700 & 0.15 & 2 & 10.5 \\
Mortar & 780 & 0.15 & 0.25 & 3 \\
Wall (Homogenous) & 3655 & 0.15 & 0.25 & 9 \\
\hline
\end{tabular}

In the numerical analysis, the Willam-Warnke fracture hypothesis is used for nonlinear behavior of the masonry wall. Willam-Warnke hypothesis is a suitable hypothesis for materials having different compressive strength and tensile strength such as masonry materials. The wall is loaded in two steps. In the first load step, the wall was loaded with a vertical pressure of $0.3 \mathrm{MPa}$ to top nodes of the wall. In the second load step, horizontal displacement is given to the top nodes of the walls. The first load step is implemented by dividing by 10 equal sub-steps. The second load step is divided into 40 sub-steps.

\subsection{Masonry Wall without Opening}

In ANSYS software the geometry of the masonry wall was created by using the macro modelling technique. Masonry units and mortar were produced as a single material. Figure 9 shows the geometry and loading for the masonry wall without opening.

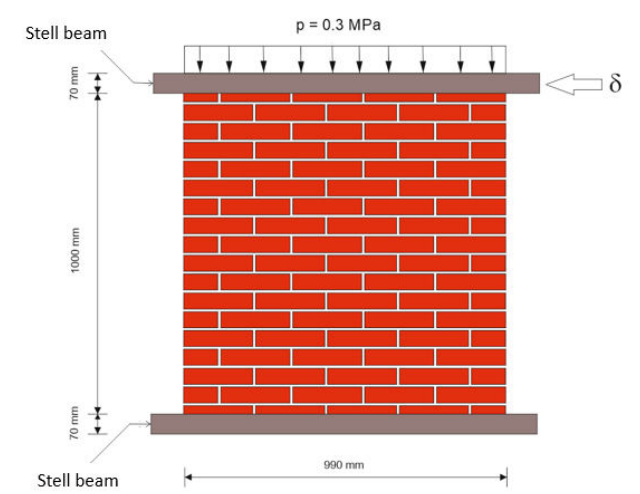

Figure 9. Masonry wall geometry and loading.

Total displacement at the end of the 1. load step, minimum principal stresses at the end of the 1. load step, minimum principal stresses at $\delta=1$, total displacement at $\delta=1 \mathrm{~mm}$ and shear stresses at $\delta=1 \mathrm{~mm}$ are shown in Figure 10. Continuous stress distribution is determined between the bricks and mortar. 


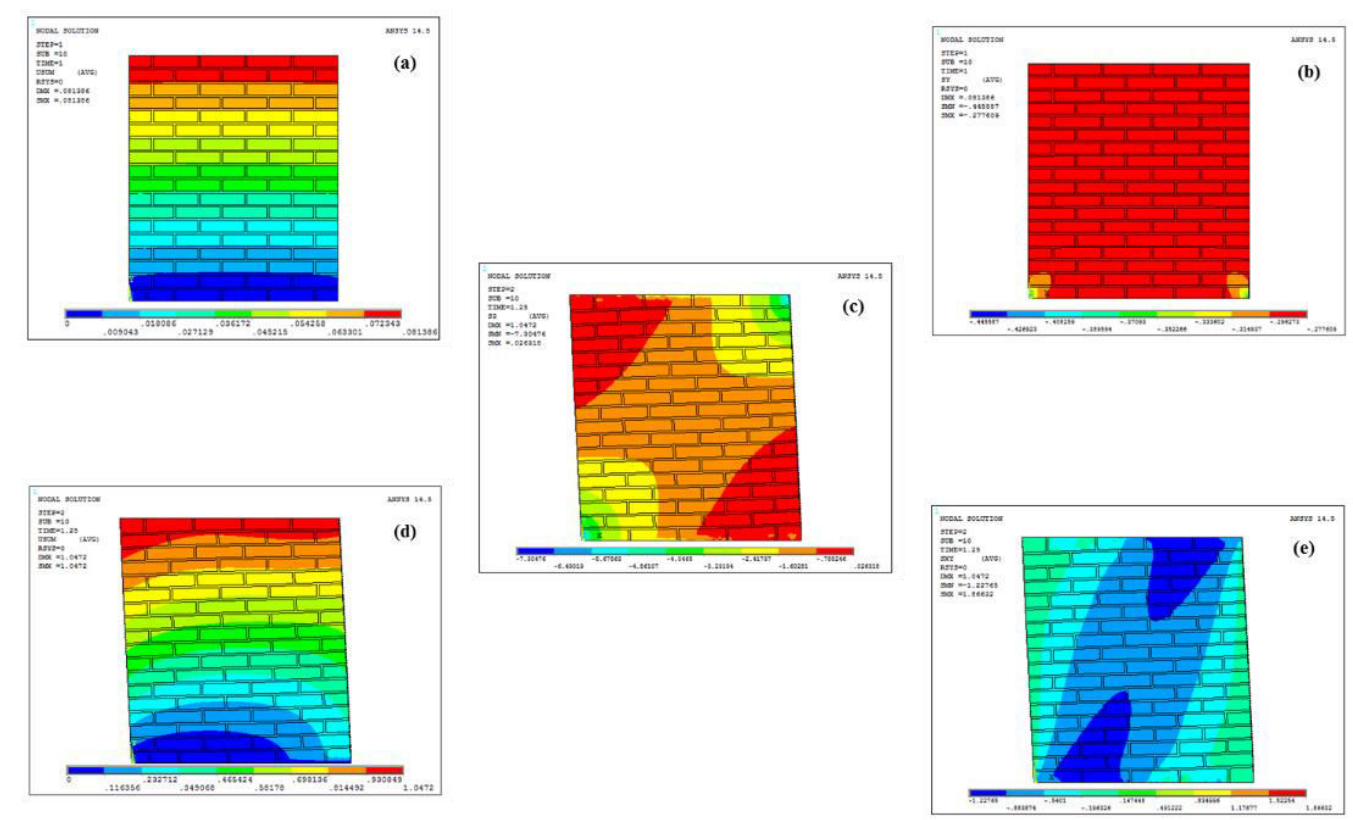

Figure 10. Masonry without opening: (a) total displacement at the end of the 1. load step, (b) minimum principal stresses at the end of the 1 . load step, (c) minimum principal stresses at $\delta=1$, (d) total displacement at $\delta=1 \mathrm{~mm}$, (d) shear stresses at $\delta=1 \mathrm{~mm}$.

The crack distribution of the unreinforced masonry wall from $\delta=0.1 \mathrm{~mm}$ to $\delta=1 \mathrm{~mm}$ is given in Figure 11 . Continuous cracks are obtained with the macro modelling technique according to finite element analysis.

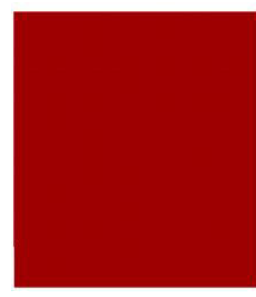

$\delta=0.1 \mathrm{~mm}$

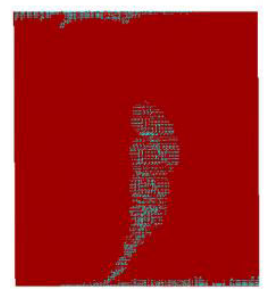

$\delta=0.6 \mathrm{~mm}$

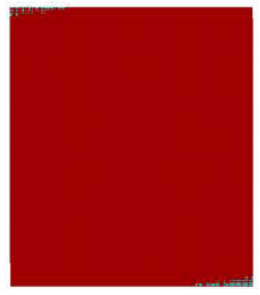

$\delta=0.2 \mathrm{~mm}$

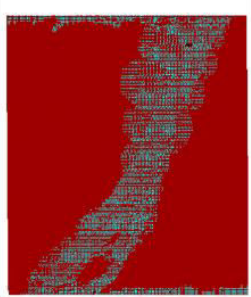

$\delta=0.7 \mathrm{~mm}$

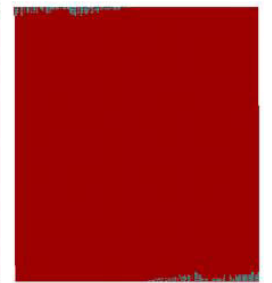

$\delta=0.3 \mathrm{~mm}$

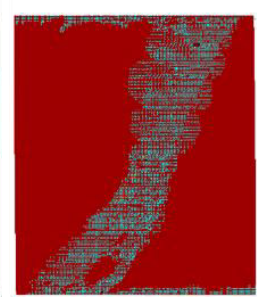

$\delta=0.8 \mathrm{~mm}$

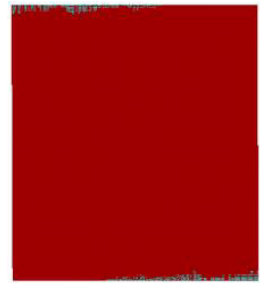

$\delta=0.4 \mathrm{~mm}$

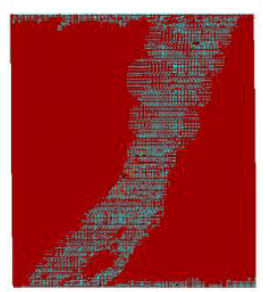

$\delta=0.9 \mathrm{~mm}$

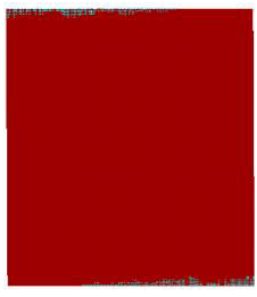

$\delta=0.5 \mathrm{~mm}$

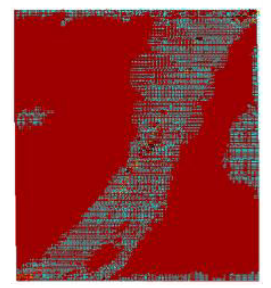

$\delta=1 \mathrm{~mm}$

Figure 11. Crack distributions for masonry wall without opening.

It is seen that the cracks first started from the upper left and lower right corners of the wall. Next, diagonal cracks occurred on the wall.

\subsection{Masonry Wall with an Opening}

Second homogenization example worked on the masonry wall with an opening. Figure 12 shows the geometry and loading for the masonry wall with an opening. 


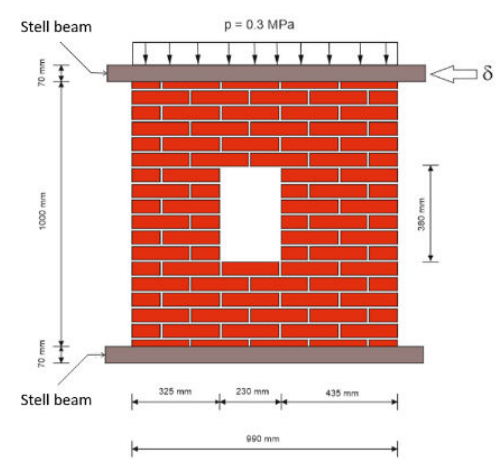

Figure 12 . Masonry wall with an opening geometry and loading.

Total displacement at the end of the 1. load step, minimum principal stresses at the end of the 1. load step, minimum principal stresses at $\delta=1$, total displacement at $\delta=1 \mathrm{~mm}$ and shear stresses at $\delta=1 \mathrm{~mm}$ according to finite element analysis are shown in Figure 13.
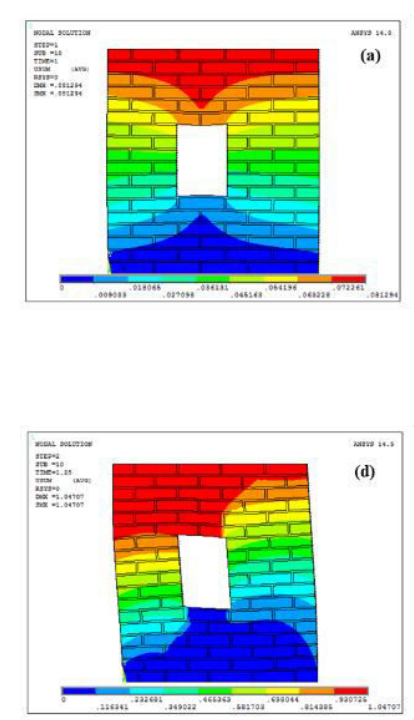
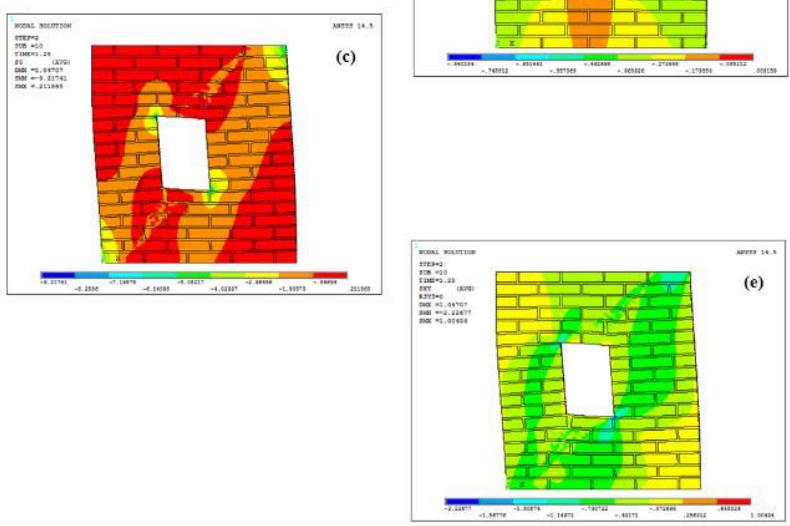

Figure 13 . Masonry with opening: (a) total displacement at the end of the 1. load step, (b) minimum principal stresses at the end of the 1. load step, (c) minimum principal stresses at $\delta=1$, (d) total displacement at $\delta=1 \mathrm{~mm}$, (d) shear stresses at $\delta=1 \mathrm{~mm}$.

The crack distributions of the unreinforced masonry wall with an opening are given from $\delta=0.1 \mathrm{~mm}$ to $\delta=1$ $\mathrm{mm}$ in Figure 14.

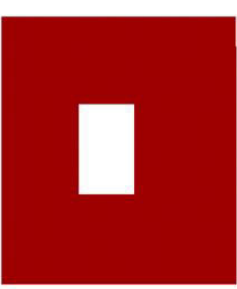

$\delta=0.1 \mathrm{~mm}$

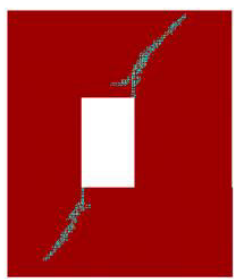

$\delta=0.6 \mathrm{~mm}$

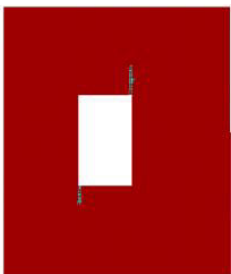

$\delta=0.2 \mathrm{~mm}$

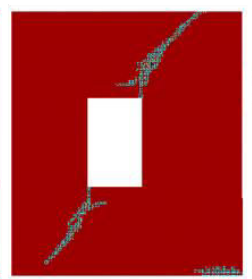

$\delta=0.7 \mathrm{~mm}$

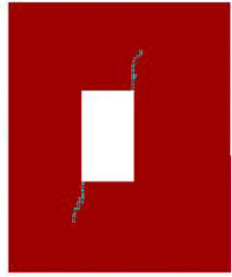

$\delta=0.3 \mathrm{~mm}$

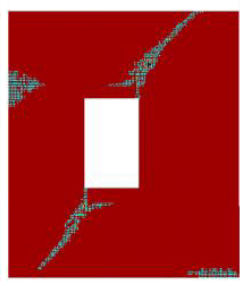

$\delta=0.8 \mathrm{~mm}$

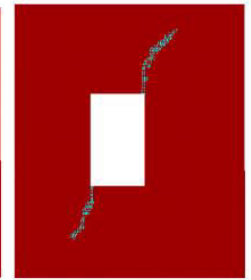

$\delta=0.4 \mathrm{~mm}$

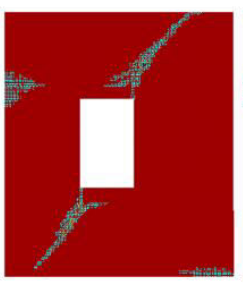

$\delta=0.9 \mathrm{~mm}$

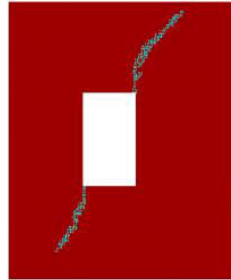

$\delta=0.5 \mathrm{~mm}$

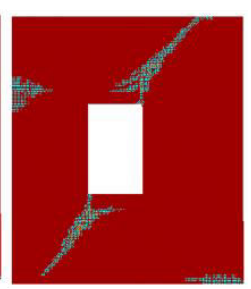

$\delta=1 \mathrm{~mm}$

Figure 14 . Crack distributions for masonry wall with opening. 
It is seen that the cracks first started from the lower left and upper right corners of the gap in the wall. In addition to the diagonal cracks on the wall, cracks are formed in the lower right part of the wall and in line with the upper left part of the opening. Finally, diagonal cracks spread to the left lower and right upper portions of the wall. And horizontal cracks spread towards to upper left and lower right corner of the wall. Finally, failure mechanism of the masonry wall with an opening idealized as four rigid blocks connected by four joints.

\section{ResultsAndDiscussion}

In this study, unreinforced masonry walls without and with an opening were modelled and analyzed using finite element method. Crack distributions were investigated step by step on the walls. The reason of the cracks can be explained in terms of internal effects. Figure 15 (a) shows the reasons of the cracks on the unreinforced masonry wall. Firstly, horizontal cracks that occur in the upper left and lower right parts of the wall shown with number (1) are tensile or shear cracks. Secondly, the cracks that occur in the upper right and lower left parts of the wall shown with number (2) are compressive cracks. Next, the diagonal cracks that occur in the middle region of the wall are represented by number (3) are caused by multiple influences.

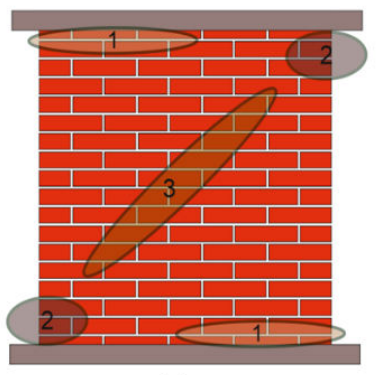

(a)

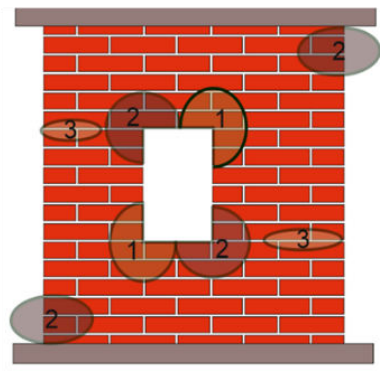

(b)

Figure 15 . The reasons of the cracks on the masonry walls.

Figure 15 (b) showsthereasons of thecracks on theunreinforcedmasonrywallwith an opening. Thecracksformed in theupperrightandleftlowercorners of thegapshownwithnumber (1) are tensile cracks. Thecracks in thelowerleftandupperrightcorners of thewallandthecracks in thelowerrightandleftuppercorners of theopeningshownwithnumber (2) arepressurecracks. Horizontalcracksstartedfromtheedge of thewallandcontinuetowardstheopeningshownwithnumber (3) areshearcracks.

Horizontaldisplacement of the top of thewallandhorizontalreactionforce of thewalldiagrams of thetwowallmodelsareshown in Figure 16. It is seenthatthemasonrywallwithoutopening has higherstrengththanthemasonrywallwithopening. But, masonrywallwith an openingrepresentsmoreductilebehaviorthanthemasonrywallwithoutopening.

Masonry Walls with and without Opening

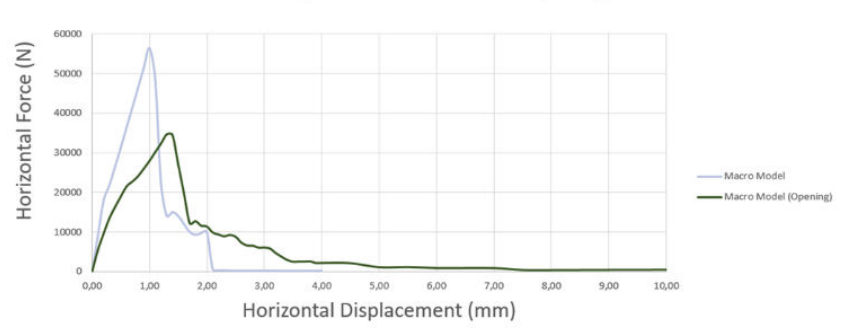

Figure 16 . Load - displacementcurves of themasonrywallmodelsaftertheanalysis.

\section{Conclusion}

The modelling technique, the material model and the fracture hypothesis form a combination for the modelling of the masonry walls. In homogenous modelling technique, single material parameters are used as an average property for masonry unit and mortar. Continuous cracks can be obtained with using homogenization technique on the walls. The strength of a masonry wall with an opening is dramatically at a lower level than masonry wall without opening but masonry wall with an opening represents more ductile behavior. 


\section{Acknowledgements}

This research has been supported financially by the ITU scientific research projects unit.

\section{References}

[1] R.D. Quinteros, S. Oller, L.G. Nallim, "Nonlinear homogenization techniques to solve masonry structures problems," Composite Structures., vol. 94, pp. 724-730, 2012.

[2] H.O. Köksal, B. Doran, A.O. Kuruscu, A. Kocak, "Elastoplastic finite element analysis of masonry shear walls," KSCE Journal of Civil Engineering., vol. 20, pp. 784-791, 2016.

[3] L. Pela, M. Cervera, P. Roca, "An orthotropic damage model for the analysis of masonry structures," Construction and Building Materials., vol 41, pp. 957-967, 2012.

[4] P.B. Lourenço, "An Orthotropic Continuum Model for The Analysis of Masonry Structures," The Netherlands, TU Delft, Report 03-21-1-31-27, 1995.

[5] Lourenço, "Computational Strategies for Masonry Structures" Doctoral dissertation, Delft University of Technology, The Netherlands, 1996.

[6] S. Oller, Numerical Simulation of Mechanical Behavior of Composite Materials, Barcelona, Spain, Springer, 2014.

[7] A.Th. Vermeltfoort, T.M.J. Raijmakers, "Deformation controlled meso shear tests on masonry piers," The Netherlands: Building and Construction Research, Eindhoven, Report B-92-1156, TNO-BOUWrrU, 1992.

[8] A.Th. Vermeltfoort, T.M.J. Raijmakers, "Deformation controlled meso shear tests on masonry piers," The Netherlands: Building and Construction Research, Eindhoven, Report B-92-1156, TNO-BOUWrrU Part 2 Draft report, 1993.

[9] L. Berto, A. Saetta, R. Scotta, R. Vitaliani, "Shear behaviour of masonry panel: parametric FE analyses," International Journal of Solids and Structures., vol. 41 pp. 4383-4405, 2004.

[10] A. Drougkas, P. Roca, C. Molins, "Numerical prediction of the behavior, strength and elasticity of masonry in compression," Engineering Structures., vol 90, pp. 15-28, 2015. 